\title{
The 3D annotated scans method: a new approach to ship timber recording
}

\author{
Thomas Van Damme ${ }^{1 *}$, Jens Auer ${ }^{2}$, Massimiliano Ditta $^{3}$, Michał Grabowski ${ }^{4}$ and Marie Couwenberg ${ }^{1}$
}

\begin{abstract}
Every year, maritime archaeologists around the globe are faced with the daunting task of recording hundreds, if not thousands, of individual ship timbers. The in-depth recording of ship timbers is a process which is both challenging and laborious, but it is an indispensable step in order to fully understand the construction of the ship the timbers formed a part of, and as archaeologists it is our duty to document all the information these complex artefacts hold to the best of our abilities. In this article, the authors first provide an overview of the methods currently in use for ship timber recording, namely 2D scaled drawing, 2D tracing, 3D contact digitising and 3D scanning. The respective advantages and limitations of these methods are then discussed in light of the various scientific and practical considerations that go into choosing a recording method for a project. Next, a new approach to ship timber recording, termed the "3D annotated scans method", is introduced and discussed using a recent case study in northern Germany. At its core the method consists of two phases; a 3D scanning phase in which the timber is scanned in 3D, followed by a 3D annotation phase in which the recorder interprets the timber by tracing diagnostic features such as fasteners and toolmarks directly onto the timber's digital model. The authors conclude that this new approach represents an improvement over current methods - both in terms of the quality of the scientific outputs and in terms of recording efficiency — and that, besides being implemented for the recording of ship timbers, the same method can also be used for a wide range of other heritage applications.
\end{abstract}

Keywords: Ship timber recording, Documentation, 3D, Scanning, Interpretation

\section{Introduction}

In any pre-industrial society, from the upper palaeolithic to the nineteenth century A.D., a boat or (later) a ship was the largest and most complex machine produced [1]. The production of those 'machines'-the process of shipbuilding-not only involved enormous resources, but also required specific skills. Adams proposes that by 'reading' ships or rather their material remains, it is possible to understand aspects of the societies that created them-aspects which would not be observable from other types of evidence [2]. An important part of 'reading' and subsequently understanding ships, is the process of recording.

\footnotetext{
*Correspondence: thomas.van.damme@outlook.com

1 Ubi3D, Antwerp, Belgium

Full list of author information is available at the end of the article
}

Within maritime archaeology, recording provides the foundation for any research and analysis that may follow. As Steffy puts it: Research and reconstruction are contributions; recording is a debt [3]. However, when it comes to the recording of ship timbers, depicting all the details of a wreck that has broken into several thousand fragments requires a great amount of effort and discipline. (...) The work can be repetitious and boring, but it is an indispensable step in accumulating all the information the wreck has to offer [3]. Ship timbers hold an enormous amount of information which is relevant to the understanding of the ship's construction, but recording ship timbers is not only laborious, it can also be challenging, particularly since ship timbers often have complicated three-dimensional shapes.

Taking the outer plank of a clinker-built vessel as an example (Fig. 1), the plank is likely curved in several directions, representing the shape of the hull it once was

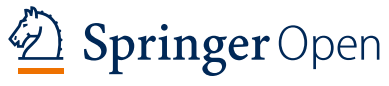

(c) The Author(s) 2020. This article is licensed under a Creative Commons Attribution 4.0 International License, which permits use, sharing adaptation, distribution and reproduction in any medium or format, as long as you give appropriate credit to the original author(s) and the source, provide a link to the Creative Commons licence, and indicate if changes were made. The images or other third party material in this article are included in the article's Creative Commons licence, unless indicated otherwise in a credit line to the material. If material is not included in the article's Creative Commons licence and your intended use is not permitted by statutory regulation or exceeds the permitted use, you will need to obtain permission directly from the copyright holder. To view a copy of this licence, visit http://creativeco mmons.org/licenses/by/4.0/. The Creative Commons Public Domain Dedication waiver (http://creativecommons.org/publicdomain/ zero/1.0/) applies to the data made available in this article, unless otherwise stated in a credit line to the data. 


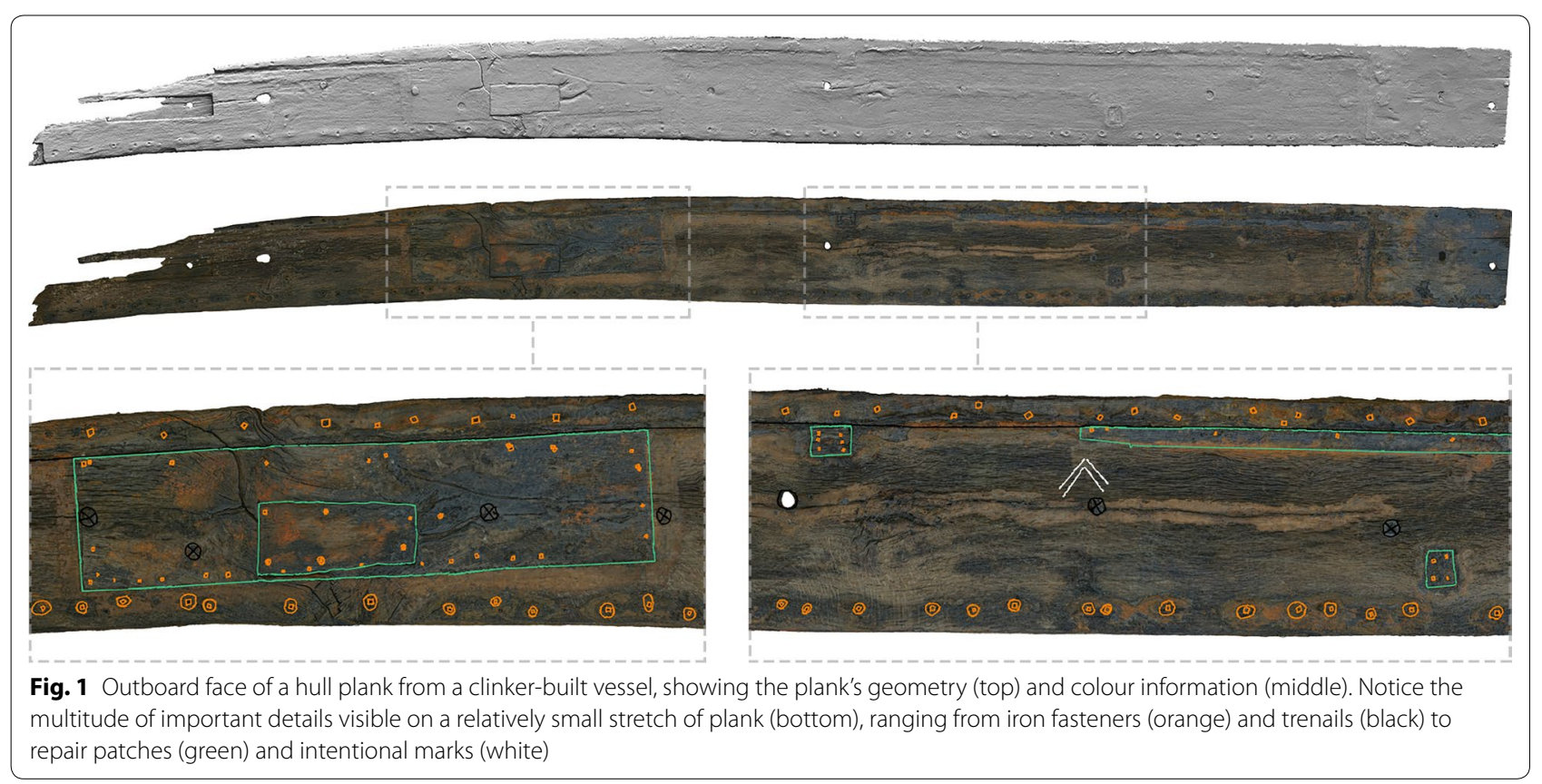

a part of. Its sections will not be uniform, but bear witness to the attachment to the planks in the strakes above and below. Both ends are shaped to scarfs, which serve to securely attach the plank to the neighbouring planks within the strake. Holes or impressions will mark the position of the different types of fastenings used to secure the plank to the remaining hull structure. The plank's inner and outer face will not only show toolmarks, but might also feature repair patches, frame impressions, decorations, or grooves to hold various types of waterproofing material. Finally, characteristics such as the wood species, the course of the wood grain and the presence of sapwood will provide clues regarding the quality of the timber, and how it was sourced from the parent tree. As such, all of these features, as well as the shape of the plank, provide relevant information and thus need to be carefully recorded in order to fully understand the construction of the ship the plank formed a part of.

While early excavations relied on analogue 2D documentation methods to record ship timbers, since the early 2000s the advent of digital 3D documentation has brought a number of advances [4-6]. However, prompted by the challenge of accurately recording a large amount of ship timbers within the short timeframe of a development-led excavation, the authors of this article revisited the recording methods currently in use and devised a novel approach which addresses some of the limitations of present methods. This new approach, termed the "3D annotated scans method" has since been used-and improved-over the course of further projects.
In this article, the authors provide an overview of current ship timber recording methods and discuss the scientific and practical considerations involved in choosing a recording method for a project. Finally, the 3D annotated scans method is presented and discussed using a recent case study in northern Germany.

\section{Current ship timber recording methods}

Over the years maritime archaeologists have explored a number of different methods to record individual ship timbers and ship timber assemblies. Although the specific tools and workflows used vary from project to project, current ship timber recording methods generally fall under one of four categories: 2D scaled drawings, 2D tracing, 3D contact digitising and 3D scanning. ${ }^{1}$

\section{D scaled drawings}

The most rudimentary method of ship timber recording, and perhaps the method most widely used for artefact recording in archaeology as a whole, is the use of $2 \mathrm{D}$ scaled drawings. In maritime archaeology, scaled drawings of timbers are typically drawn on grid paper at scale $1: 10$, though a larger scale is sometimes used, particularly if the timber in question contains a lot of features in

\footnotetext{
${ }^{1}$ Strictly speaking, when discussing ship timber recording, the term 'recording' may incorporate a wide range of different techniques with vastly different outputs, including simple written descriptions, basic sketches, photographs, traditional (non-orthographic) photomosaics, X-Ray imaging and Reflectance Transformation Imaging. In this paper we will limit our discussion to methods for producing faithful, scaled, visual records of individual ship timbers.
} 


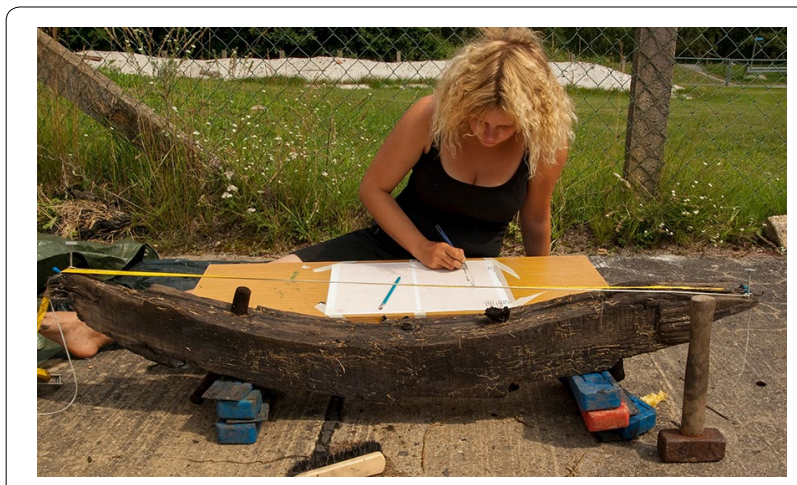

Fig. 2 Recording a ship timber using 2D scaled drawings

close proximity to one another. Measurements for scaled drawings can be done using any combination of simple measuring tools including tape measures, rulers, callipers, protractors (for measuring angles), grid tables and drawing frames (Fig. 2). While drawing, different colour pencils or markers may be used to differentiate between various feature types $[3,7]$.

\section{D tracing}

A second method traditionally used to record ship timbers is full-sized 2D tracing, often referred to simply as 1:1 tracing. Full-sized 2D tracing involves placing a transparent sheet or film directly on (direct tracing) or above (elevated plane tracing) the timber and then tracing the timber outlines and features onto the recording sheet with a marker (Fig. 3). Again, different colour markers may be used to identify different feature types. After recording, the 1:1 tracings are typically scaled down to a more manageable size for further research and publication. Full-sized tracings have traditionally been redrawn by hand or reduced photographically; today the use of a large format scanner would appear to be the most practical solution $[3,5,7,9]$.

\section{D contact digitising}

In recent decades, with the advent of new technologies and more powerful computers, many shipwreck projects have shifted from analogue $2 \mathrm{D}$ to digital $3 \mathrm{D}$ recording methods. In particular, over the past 20 years or so, contact digitising has emerged as the best practice method for ship timber recording. Contact digitising involves tracing all significant features and outlines of a timber using the pen of a coordinate measuring device, which tracks and records the precise 3D location of the penpoint (Fig. 4). Typically the traced 3D coordinates are recorded in real-time as $3 \mathrm{D}$ polyline wireframes in the CAD software Rhinoceros, with different layers in Rhino representing different feature types. The best-known and most widely used tool for this approach is the FaroArm, though other coordinate measuring devices such as the wireless Creaform HandyPROBE have also been used [5, 6].

Within the field of maritime archaeology the FaroArm was first used at Mystic Seaport in the US in the mid1990 s to record ship's models. For timber recording, use of the FaroArm and Rhino 3D was pioneered by the National Museum of Denmark in 2001 to record 56 timbers of the Kolding Cog; since then contact digitising has seen widespread adoption on numerous prominent shipwreck projects including the Roskilde wrecks, the
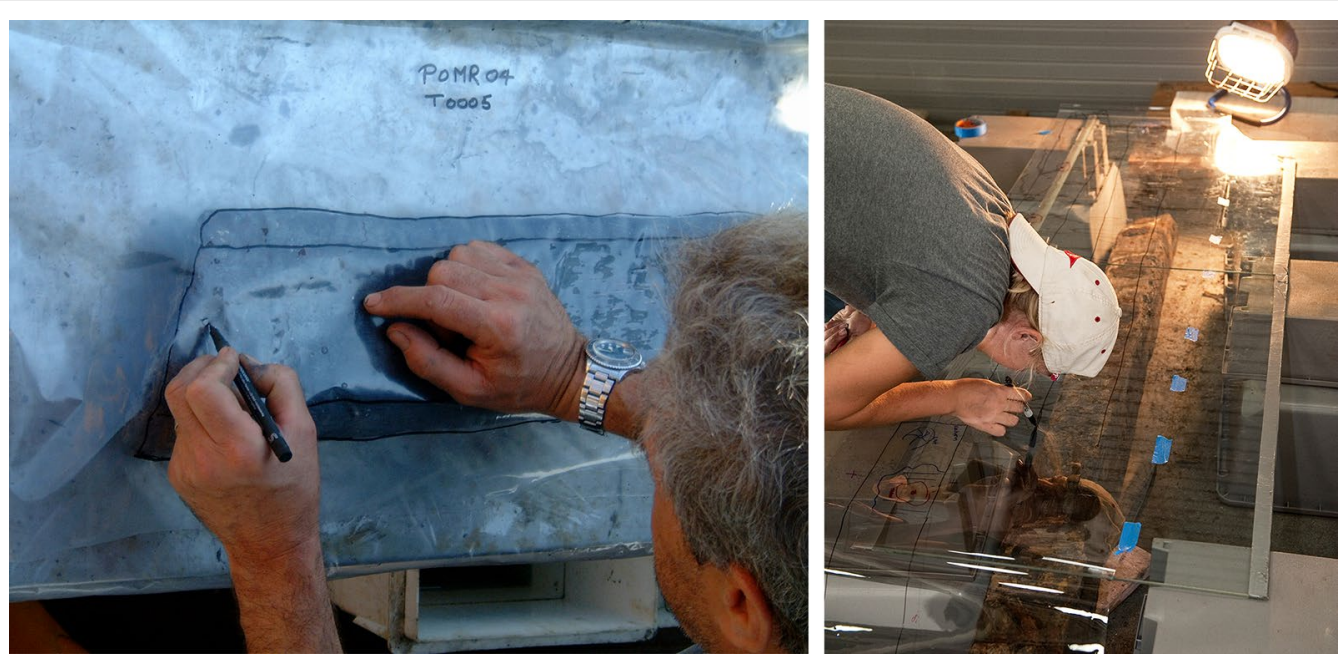

Fig. 3 Ship timber recording using the direct tracing method (left) and elevated plane tracing method (right). Pictures reproduced with permission of Kester Keighley [7] and Drew Fulton [8] 


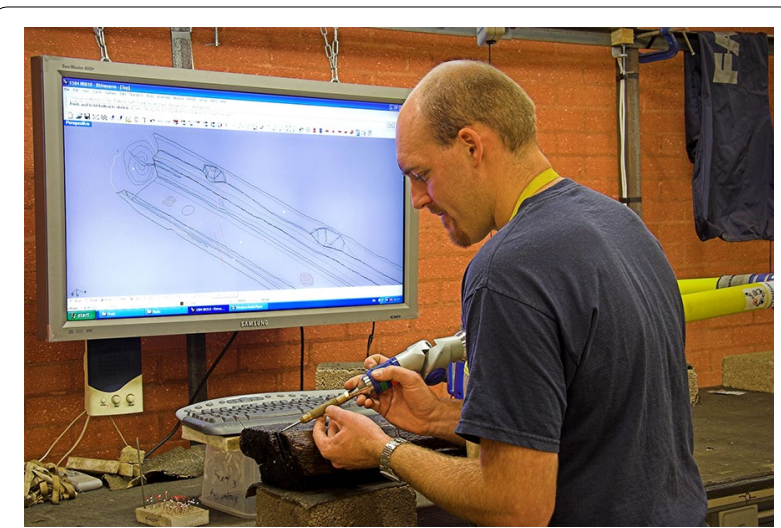

Fig. 4 Recording a ship timber using a FaroArm 3D contact digitiser. Picture by Rex Moreton, reproduced with permission of the Newport Museums and Heritage Service [5]

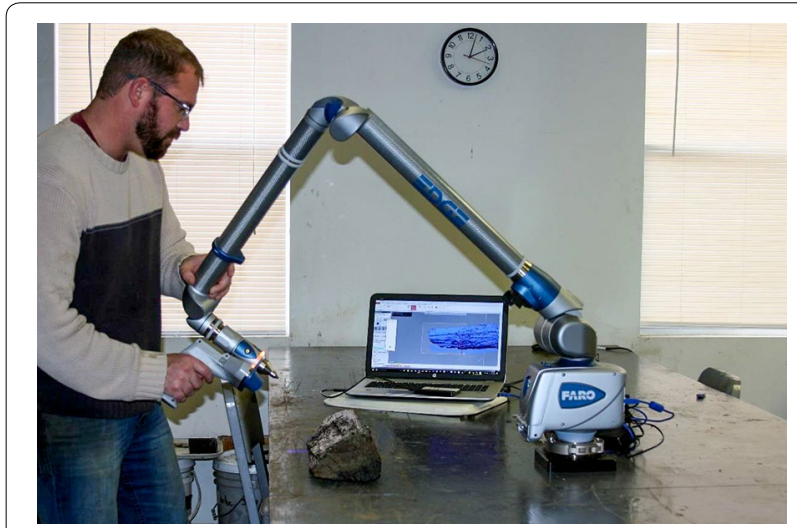

Fig. 5 3D scanning a ship timber, in this case using a laser line probe attached to a FaroArm. Picture reproduced with permission of Christopher Dostal [10]

Newport Ship, the Drogheda Boat, the Doel Kogge Project, several of the Yenikapı shipwrecks and Arles-Rhône $3[5,6]$.

\section{D scanning}

A more recent but growing trend in maritime archaeology is the practice of recording individual ship timbers using 3D scanning (Fig. 5). For this purpose, a range of different 3D scanning methods can be used, including laser scanning, structured light scanning and photogrammetry $[4,5,10]$. Within each of these overarching techniques, researchers can in turn choose between a range of different hardware, software and workflow options. No two approaches are the same, and the specific tools and workflows used will influence both the accuracy and resolution of the 3D scans, as well as whether the scans contain both geometry and colour information, or only geometry. Regardless of the method chosen, the end result of the 3D scanning procedure will be a scaled digital 3D copy of the physical timber, typically in point cloud or mesh format.

Shipwreck projects on which all or most (loose) structural timbers have been individually recorded using some form of 3D scanning include the Mönchgut 92 wreck, the Polish Copper Ship, the World Trade Center Ship, the wreck of the Royal Savage and the cog, river barge and punt excavated during the IJsselcog Project [10-14].

\section{Considerations when choosing a recording method}

When deciding between different recording methods, researchers evaluate a method based on the quality of its scientific results, as well as on certain practical factors such as the cost and time expenditure associated with each method. In this section we will discuss the main considerations to keep in mind when choosing a recording method, in light of the four timber recording methods discussed above.

\section{Scientific considerations Accuracy}

Perhaps the primary concern for maritime archaeologists when considering different timber recording methods is the method's accuracy. In other words: to what degree do the resulting timber records correctly portray the actual physical timbers? The accuracy of a given timber drawing or 3D model may be influenced by a host of different factors, including the specific workflow and tools used, the artistic and technical skills of the recorder, as well as the recorder's level of focus, dedication and attention to detail at the time of recording. In the hands of a capable recorder, each of the recording methods discussed above may produce highly accurate timber records. As such, the question is not whether the different methods are capable of producing accurate timber records, but rather: can they do so consistently? Put another way: for each recording method, what is the likelihood of errors or inaccuracies creeping into the timber records?

Of the timber recording methods discussed, 2D scaled drawings are most prone to human errors; the accuracy of the drawings depends entirely on the person doing the recording. Accurately measuring and subsequently transferring every outline and feature of a timber to a scaled drawing requires skill, focus and dedication. It is easy to make small measurement errors using manual tools, and even two experienced recorders may obtain slightly different measurements on the same timber [10].

$2 \mathrm{D}$ tracing reduces the risk of human errors as the recorder can simply trace the outlines and features of a timber, rather than having to measure and draw them. Nevertheless, this method is susceptible to other inaccuracies. Direct tracings of curved timbers such as 
planks will result in distortions along the lengths of the timbers; the resulting drawing will be a flattened representation of the timber, rather than a true orthographic drawing. Such distortions can be avoided using elevated plane tracing, but this in turn introduces the possibility of parallax error: timber outlines close to the tracing surface are relatively easy to trace accurately, but outlines farther away may accidentally be traced at an offset from their true orthographic projection on the tracing surface. Parallax error can be mitigated by adding control measurements across the length of a timber drawing, or by using a laser guide while tracing. Finally, with $2 \mathrm{D}$ tracing some projects have noted stretching of the tracing sheets, and care must be taken to ensure that no distortion or scaling errors are introduced when the 1:1 tracings are scaled down $[4,5,7,9,10,15]$.

Similar to 2D tracing, 3D contact digitising reduces the risk of human measurement or drawing errors as the recorder simply traces the outlines and features of the timbers. Furthermore, since the timber is recorded in three dimensions, the potential distortion or parallax errors discussed with $2 \mathrm{D}$ tracing are no longer a concern. Finally, as the recording is made and stored directly in a digital format, researchers needn't worry about stretching of timber sheets, and timbers can be displayed at any desired scale without the risk of introducing scaling errors. When properly calibrated, devices like the FaroArm have a stated accuracy of less than a millimetre, meaning that so long as the recorder takes care to position the tip of the recording pen directly on the outline or feature being traced, its $3 \mathrm{D}$ coordinates will be mapped with incredible precision and accuracy $[4,5]$. Inaccuracies may still be introduced, for instance if the timber is accidentally moved during recording, but this holds true for any recording method. Perhaps of more concern are flexible timbers. To produce a full 3D record of a timber using contact digitising, the timber must be turned over at least once. When turning over a flexible timber such as a plank, care must be taken to ensure that the timber does not change shape, else the resulting overall $3 \mathrm{D}$ model of the timber will be warped, even if this is not immediately apparent to the observer. This is mitigated to some extent by inserting fixed points such as metal screws at intervals along the entire length of the timber prior to recording. The coordinates of these reference points are measured with the contact digitiser when the timber is in its first position, and are then measured again once the first side has been recorded and the timber has been turned over. If the reference points of the second timber position don't adequately match up to the reference points of the first timber position, the software will issue a warning, indicating to the recorder that the timber has changed shape and needs to be supported differently before proceeding with the rest of the recording [5].

Barring any intentional modifications to the timber record (in bad faith or otherwise), 3D scanning is the timber recording method least prone to human errors, as very little manual input is typically required. Instead, the accuracy of a given 3D scanning technique will depend largely on the scanning hardware, software algorithms and processing workflow used. As with contact digitisers, most 3D scanning hardware will have a stated accuracy, and when properly calibrated, the high-end laser scanners or structured light scanners currently being used for timber recording are generally considered extremely accurate. The 3D scanning method which receives most scrutiny regarding its accuracy (or lack thereof) is photogrammetry, but in the authors' opinion this concern is often overblown, particularly when discussing objects which have been recorded from all sides (left, right, front, back, top and bottom - and everything in between), such as timbers. It is true that, unlike most other $3 \mathrm{D}$ scanning techniques, photogrammetry does not have a predefined accuracy range. Instead, the accuracy of a given photogrammetric model will vary depending on a host of different factors such as the camera and camera settings being used, the quality of the individual images, the quality of the overall photo sequence, the distance from which the pictures were taken, the accuracy of the reference information used to scale the photogrammetry model, as well as the processing workflow and software used. Nevertheless, the fact is that, when performed correctly, with a fixed lens, with camera calibration parameters held constant throughout the entire photoset, and with photos of all sides of the timber compared to one another using capable computer vision photogrammetry software, there is very little wriggle room for the software to calculate erroneous camera positions or surface geometry. The one step where errors can easily be introduced is when scaling the photogrammetry model to real-world dimensions; it is important that several reliable, sufficiently long, scale bars be used to scale the model, or that the model is scaled using reference points positioned around the timber which have been measured using an accurate coordinate measuring device such as a total station.

No matter which 3D scanning method is used, occasional errors or inaccuracies will still occur: the scanning device may be poorly calibrated, scattered laser beams reflecting off a wet timber might register as surface details rather than background noise, or a timber may have subtly shifted during scanning. However, unlike 3D contact digitising, all 3D scanning methods including photogrammetry have the advantage that, if 
the resulting 3D model does contain erroneous geometry, the error is often glaringly obvious to the observer. To return to our example of a flexible plank: if a plank is scanned, turned over, scanned again, and the two scans are subsequently merged, any change in the shape of the plank will be immediately evident, as the two scans of the plank won't match up in the overall 3D model. One potential pitfall with this is what some researchers have called the "ruse of realism", namely that 3D models resulting from 3D scanning look so realistic that we take their accuracy for granted, even if this realism might mask certain inaccuracies [10]. While this is certainly something to keep in mind, as far as timber recording is concerned this appears to be mostly a theoretical concern; the authors don't know of any concrete examples where seemingly accurate 3D scans of timbers have turned out to be considerably inaccurate upon closer inspection with other recording methods.

As pointed out by Dostal, discussions on the accuracy of timber recording may also go beyond mere geometric accuracy [10]. As an example, a timber scan performed using a laser line probe may be highly geometrically accurate, but be blatantly inaccurate in a different way: the timber is shown in a single monotonous colour, rather than the multitude of different colours visible on the surface of the actual timber. A textured photogrammetry scan of the same timber might be less geometrically accurate, but will certainly be more accurate in terms of correctly portraying the timber's colours. This colour information may contain clues that are relevant to the understanding of the timber-such as orange oxidation stains (indicating the position of an iron nail) or variations in wood colour (perhaps indicating the difference between sapwood and heartwood)-which are not visible on the 3D model produced using the laser line probe. As such, whether or not a given 3D scanning method captures colour information may also be something to take into consideration when choosing between different 3D scanning techniques. Additionally, returning to the issue of flexible timbers: how does one define the accuracy of the timber record of a flexible timber, such as a plank or even a keel? A waterlogged keel will often sag or warp when turned over, so two scans of the same keel may both accurately portray the timber at the time of recording, but will each show the keel in a different shape. Is one more accurate than the other? Can we only speak of an accurate timber record if the timber is recorded in the shape it likely had in the original vessel? Or should one attempt to record the timber in the shape it was found, possibly flattened by years of deposition on the seabed?

\section{$2 D$ vs $3 D$}

The most important limitation of $2 \mathrm{D}$ scaled drawings and $2 \mathrm{D}$ tracing is the fact that-no matter how much effort a researcher puts into accurately portraying a timber-the final drawing is still a two-dimensional simplification of a complex three-dimensional artefact. Our world, and most of the objects in it, are three-dimensional; any two-dimensional recording fundamentally represents a loss of information. It is therefore the belief of the authors that archaeologists should always strive to document sites and artefacts in all three dimensions whenever possible, particularly now that 3D documentation methods are so readily available. This holds especially true for objects with inherently complex geometric shapes such as ships or ship timbers. It is always possible to reduce a complex 3D model of a timber to a $2 \mathrm{D}$ representation as needed, for instance for use in a 2D timber catalogue; the reverse is not possible, at least not without resulting in a significantly simplified representation of the original timber.

Furthermore, recording archaeological artefacts in three dimensions rather than two opens up a wide range of practical tools for analysing, interpreting, conserving and displaying these artefacts $[5,6]$. For instance, 3D models of ship timbers can be reassembled digitally in CAD software, or 3D printed and reassembled physically. This 'as found' reconstruction then allows researchers to analyse the original hull form, and ultimately, if the wreck is sufficiently preserved, it can serve as the basis for creating a tentative reconstruction of the original vessel. In terms of public dissemination, using the original 3D records, animations can be made showing the wreck being digitally reassembled through its various construction phases, giving the public a better understanding of how the vessel was originally built. 3D models can also be readily shared online, and often present a more engaging, understandable format for public viewing when compared to traditional 2D drawings. In terms of conservation, 3D recording of ship timbers both before and after conservation allows researchers to better analyse and understand deformations caused by the conservation treatment. In the future, conservation specialists may use $3 \mathrm{D}$ scans of timbers to create custom-built moulds for each timber, which could be used to prevent deformation during conservation treatment, or even to intentionally deform a timber in such a way that it regains the original shape it likely had before archaeological deposition. If the intention is to reassemble the wreck physically for museum display, 3D models of the timbers can help in planning the reconstruction process, and can be used to design a custom support structure to ensure that the wreck does not sag either during or after reassembly. 


\section{Interpretation vs scanning}

$2 \mathrm{D}$ scaled drawings, $2 \mathrm{D}$ tracing and $3 \mathrm{D}$ contact digitising are all interpretative recording methods, meaning that the person doing the recording has to examine and analyse the timber in question, and subsequently records the information he or she considers significant at that time. 3D scanning is different in that the person doing the recording need not actually examine the timber; the scanning tool simply indiscriminately records all information it can perceive, without any input concerning the value or meaning of that information on the part of the recorder.

Researchers have made valid arguments highlighting the purported advantages or limitations of either approach $[4,5,10,16]$. The interpretative recording methods force the researcher to be up close and personal with the timber and to actually think about what he or she is recording. This helps to ensure that important details such as toolmarks, intentional marks or repair patches don't go unnoticed, and it allows the researcher to gradually form an idea of the unique features and potential construction sequence of the wreck, all while recording. The downside is that these methods rely on the skill and motivation of the recorder to correctly observe and portray all relevant information. Even the most experienced and dedicated maritime archaeologists will occasionally miss or misinterpret a feature, and after recording the only way to check the record would be to return to the actual timber. Finally, any interpretative recording method can never be truly objective or complete: the recorder must always make some subjective decisions regarding which type of information to include or exclude, how much information to include and how to interpret or present this information.

3D scanning techniques don't rely on the archaeological skill or experience of the recorder, and will objectively and consistently record every detail visible to the scanning device. As such, 3D geometry (and depending on the scanning technique, also colours) will be documented to a degree that is simply unattainable with other methods such as contact digitising; every slight indentation or change of shape in the timber will be portrayed in the 3D model. Furthermore, important features such as nail holes or trenails will generally be sufficiently visible on the 3D scans to allow for digital or physical (after $3 \mathrm{D}$ printing) reassembly of the wreck. As such, while the recording of the individual timbers might not be interpretative, this does not mean that the resulting 3D scans lack all interpretative potential. Nevertheless, if 3D scanning is considered 'sufficient', this begs the question what the role of the archaeologist is in timber recording; one might as well leave all recording to a 3D scanning specialist and omit the archaeologist altogether.
The simple truth is that, by only 3D scanning timbers, an indispensable step in interpreting the individual timbers and eventually understanding the shipwreck as a whole, is skipped. An experienced maritime archaeologist carefully studying the actual physical timbers will invariably note details which might not be apparent on the 3D scans. Furthermore, while 3D scans may contain a lot of raw data, this data has not been filtered for relevance. As such, the fact that the interpretative recording methods only portray relevant information can be an advantage: to a maritime archaeologist, a line drawing of a timber made using $2 \mathrm{D}$ scaled drawing, $2 \mathrm{D}$ tracing or $3 \mathrm{D}$ contact digitising will often be easier to 'understand' at a glance when compared to the abundance of information visible in a $3 \mathrm{D}$ scan.

In recognition of these limitations, many shipwreck projects that have used 3D scanning for timber recording have supplemented the resulting 3D scans with some form of interpretative recording. In the case of the Mönchgut 92 wreck, all timbers were simply recorded a second time using contact digitising [11]. In the case of the IJsselcog Project and the World Trade Center Ship, $2 \mathrm{D}$ renders of the $3 \mathrm{D}$ scans were annotated by archaeologists after scanning (thereby unfortunately again simplifying the $3 \mathrm{D}$ record to a $2 \mathrm{D}$ format for interpretation) $[10,13]$.

\section{Practical considerations}

Besides the scientific considerations discussed above, the reality is that, when choosing between different recording methods, project leaders must also balance various practical considerations. Ideally, timbers aren't removed from a shipwreck site until a method of preservation or conservation has been agreed upon, and sufficient time and funding have been secured to carry out both the excavation and the subsequent recording of the wreck's timber assembly, as well as the analysis and publication of the results. In this case the project leader has time to carefully plan the project budget and timeframe, and to assemble a team with the relevant expertise to carry out the timber recording, often in a secure and well-equipped laboratory setting. Nevertheless, as any maritime archaeologist can attest, the reality on the ground is often far from ideal, and as such practical considerations may vary greatly from project to project; a well-funded and well-planned research excavation will face very different practical constraints when compared to for instance a last-minute rescue excavation.

\section{Cost and time efficiency}

Foremost among the practical considerations to take into account on any timber documentation project, are the cost and time efficiency of different recording methods. 
Even when a project has access to considerable time and funding, it would appear wasteful to use a slow or expensive recording method when a faster or cheaper method can achieve comparable or better scientific results.

The most obvious cost associated with each recording method is the upfront cost of the tools needed to carry out the recording: the price of the required hardware and in some cases software. In this regard 2D scaled drawings and 2D tracing are clearly the cheapest methods; some simple manual tools are all that is required to start recording. In comparison, contact digitisers and 3D scanning hardware such as handheld scanners, terrestrial laser scanners and laser line probes are often very expensive $[4,5,10]$. Out of the 3D scanning methods discussed, hardware costs are lowest for photogrammetry, which requires only a decent camera. In addition to the initial purchase cost of the recording device, some 3D scanning hardware also comes with steep maintenance costs, and the necessary computers and software to process and manipulate the $3 \mathrm{D}$ results can likewise take a significant chunk out of the project budget. As such, on some projects the upfront costs of 3D recording may simply be prohibitively expensive. Nevertheless, new hardware and software is becoming increasingly affordable as the $3 \mathrm{D}$ recording market matures, and good equipment can often be bought second hand. Finally, for many projects the most cost-efficient option might be to simply rent or even borrow a 3D recording device, since a lot of recording hardware sits unused between projects.

A second-less evident, but in many cases more significant-factor influencing the final cost of a recording method is time expenditure. The more time is needed to record the timber assembly, the more money will be spent on staff wages and other project operating costs such as warehouse rental and staff accommodation. As such, whether or not time expenditure has a meaningful impact on the overall project cost will depend on the project; it may be less of a concern on projects with very few timbers, on projects which don't have to worry about location rental, or on projects which can rely on cheap or free labour. By contrast, it will be an extremely important factor on most large development-led shipwreck projects. Time expenditure may also be relevant for reasons other than costs: many shipwreck projects simply face strict time constraints, and in order to avoid timber deterioration it is generally advisable to keep timbers in temporary storage for as little time as possible during the recording phase.

Accurately recording every face of a timber using $2 \mathrm{D}$ scaled drawings is extremely time-consuming, so even though pencils, rulers and grid paper are cheap, the total cost of recording may be high compared to other methods. 2D tracing requires a bit more preparation but will generally be faster overall, especially on larger timber assemblies. After conducting a thorough preliminary assessment of different recording methods, researchers on the Newport Ship Project concluded that, for this large-scale project, 3D contact digitising would be more time efficient than manual $2 \mathrm{D}$ recording methods $[5,16]$. Even so, Jones has estimated that, on average, over the course of the project, a FaroArm user with at least 1 month of experience needed about $4 \mathrm{~h}$ to record a plank and $6 \mathrm{~h}$ to record a frame (5; Jones 2018, personal communication). The average time spent on a given timber will vary per project depending on the size of the timbers and the number of features per timber, as well as on the skill of the recorders, so it is impossible to extrapolate these figures to other projects. Nevertheless, the Newport Ship Project is generally considered one of the most efficient implementations of 3D contact digitising, and these recording times are still substantial. In addition, once the timbers had been recorded, converting the $3 \mathrm{D}$ polyline wireframes into $3 \mathrm{D}$ solids for CAD modelling or 3D printing required, on average, a further $2 \mathrm{~h}$ per timber (5; Jones 2018, personal communication). Although this last step does not form part of the timber recording itself, the time needed to produce useful 3D outputs for further analysis may also be a factor to consider when deciding on a recording method. A final problem is that, while a single researcher might be able to record more timbers per day with a contact digitiser than with traditional recording methods, the main bottleneck with contact digitising is the hardware itself. With 2D scaled drawings or 2D tracing any number of researchers can work in parallel, each recording a different timber. By contrast, with 3D contact digitising, per contact digitiser only one researcher a time can be at work recording a timber, meaning that the only way to speed up recording is to acquire additional contact digitisers, which, as we have seen above, are rather costly.

In comparison, the timber recording output 'per person, per device' is vastly greater with $3 \mathrm{D}$ scanning methods, which typically allow a single researcher to scan many timbers in very little time. Specific recording and processing times will vary depending on the 3D scanning tools and workflow used, but to give some examples, on the World Trade Center Ship up to 5 timbers a day could be scanned and processed using a laser line probe [10], on the IJsselcog Project up to 12 timbers a day were recorded and processed using photogrammetry [13] and 51 timbers of the Royal Savage were scanned (but not processed) in a single afternoon using a terrestrial laser scanner [12]. 


\section{Required technical expertise}

Another practical consideration which may influence the choice of timber recording method is the technical expertise required to use each method. Whereas most maritime archaeologists are already trained in $2 \mathrm{D}$ scaled drawing and can quickly become proficient in $2 \mathrm{D}$ tracing, $3 \mathrm{D}$ contact digitising and $3 \mathrm{D}$ scanning require a certain level of technical expertise, and the relevant skills are not traditionally taught in maritime archaeology courses. Learning how to work with 3D recording hardware and software requires training, and not every researcher has the insight and computer skills needed to overcome the obstacles that inevitably come up when recording in $3 \mathrm{D}$. Again, this issue ties into cost and time efficiency; for a large pre-planned project it will often make sense to train researchers in new 3D recording methods or to hire outside expertise, while for small impromptu projects it might be more sensible to simply stick to the recording methods the team already has at its disposal.

A related issue is the matter of how much technical expertise is required for other researchers to access and examine the timber records once recording has been completed. Although 3D records contain a lot of data, this data will be of little use if it can't be opened in the software packages researchers have available, or if researchers are simply not trained in the use of 3D software $[10,17]$. As such, when working with 3D documentation methods it is important to ensure that the resulting timber records are accessible in digital formats which are widely used, and which are likely to stand the test of time. Additionally, even when timbers have been recorded in $3 \mathrm{D}$, it is still considered good practice to include a $2 \mathrm{D}$ timber catalogue in the final publication, so that the archaeological data remains accessible (albeit in a simplified form) to researchers without the necessary software or technical background to view the original 3D records [10].

\section{Ease of use in the field}

Many shipwreck projects opt to record timbers in a laboratory or warehouse setting, but on some projects this might not be possible (due to financial or time constraints) or desirable (for instance if the intention is to briefly bring up a timber from a wreck site for recording, and subsequently redeposit it). In such cases, a timber recording method's ease of use in the field will be an important consideration. Some recording methods, such as $2 \mathrm{D}$ scaled drawing or photogrammetry, can easily be used on site, whereas others, such as contact digitising or certain types of structured light scanning, are more suited to a secure laboratory environment.

\section{Opting for a different approach}

The discussion above highlights some of the limitations of current ship timber recording methods and illustrates that there is still room for improvement. During the planning phase for a large-scale excavation of two 18th Century shipwrecks-Mönchgut, Ostsee VII, Fpl. 63 and Fpl. 64-as part of the mitigation for the Nord Stream 2 offshore gas pipeline, the need for a different approach to timber recording became very apparent [18]. The project set a number of specific demands:

- Scientific considerations: The excavated ship timbers would not be conserved, but instead stored in an underwater depot, and would therefore not be easily accessible for future research; any recording would have to be considered final. As such the recording method of choice had to allow for highly accurate recording, and the archaeological interpretation had to form an integral part of the primary recording process. It was decided that a lack of recording accuracy should not be a limiting factor for further research or analysis of the wrecks. Furthermore, given the limitations of 2D recording discussed above, it was deemed essential to record the timbers in 3D.

- Practical considerations: The recording method of choice would have to be time efficient to allow for simultaneous excavation of the shipwrecks and recording of the recovered timbers, without accumulating a large backlog in either process. While the availability of technical expertise was not seen as a major problem, the ability to use the method in a temporary recording tent under less than ideal conditions was considered important in order to limit handling and transport of the archaeological timbers.

As such, archaeological requirements, operational limitations and time constraints meant that none of the traditional recording methods outlined above were entirely suitable. $2 \mathrm{D}$ scaled drawings and $2 \mathrm{D}$ tracing would not produce the required $3 \mathrm{D}$ results, $3 \mathrm{D}$ contact digitising was considered too time-consuming and the necessary hardware would be ill-suited for use in our temporary recording laboratory, and merely $3 \mathrm{D}$ scanning the timbers was deemed insufficient, since it would omit the in-depth archaeological interpretation of the individual timbers.

As a result, a new approach to timber recording was developed. The method was first successfully implemented during the documentation of the two 18th Century shipwrecks, and was subsequently refined on the Wismar Big Ship Project, which will be examined in more detail as a case study below. 


\section{The 3D annotated scans method Conceptual framework}

The basic concept behind the 3D annotated scans method is straightforward and consists of two phases: a 3D scanning phase followed by a 3D annotation phase. During the first phase, the timber is simply scanned in 3D. The authors have obtained good results with both structured light scanning and photogrammetry, but any 3D scanning method which results in accurate threedimensional information on both the timber's geometry and colour can be used. In order to integrate archaeological interpretation into the recording process, the 3D scanning phase is then followed by the $3 \mathrm{D}$ annotation phase. An archaeologist proceeds to interpret (or annotate) the ship timber by tracing the timber's diagnostic features directly onto the timber's digital 3D model. During this phase it is essential to still have the actual physical timber available; even high-resolution geometry and texture (colour) data cannot serve as a replacement for the physical object when it comes to recognising details such as repairs and small fastenings. For 3D annotation the authors opted to use the CAD software Rhinoceros, but any software which allows the researcher to trace features directly onto a 3D model's surface can be used.

\section{Case study: the Big Ship of Wismar}

A preliminary assessment after the Mönchgut, Ostsee VII, Fpl. 63/64 Project clearly showed the benefits of the $3 \mathrm{D}$ annotated scans approach to timber recording. A few months after the first project, the opportunity presented itself to build on this experience and further refine the method, when a well-preserved 12th Century shipwreck was excavated and recovered by the State Authority for Culture and Monuments in Mecklenburg-Western Pomerania (LAKD M-V). The 20 by $4 \mathrm{~m}$ wreck was discovered at $5 \mathrm{~m}$ depth during construction works in the harbour of Wismar, a city on the Baltic Sea in the northwestern part of the state [19].

After excavation, the shipwreck was disassembled under water and lifted in pieces. The timbers were then transported to the LAKD M-V conservation facility in Schwerin, where they were stored in large collapsible water basins until they could be recorded. Altogether 316 whole ship timbers and parts or fragments of ship timbers were cleaned and registered. Of these, 240 timber

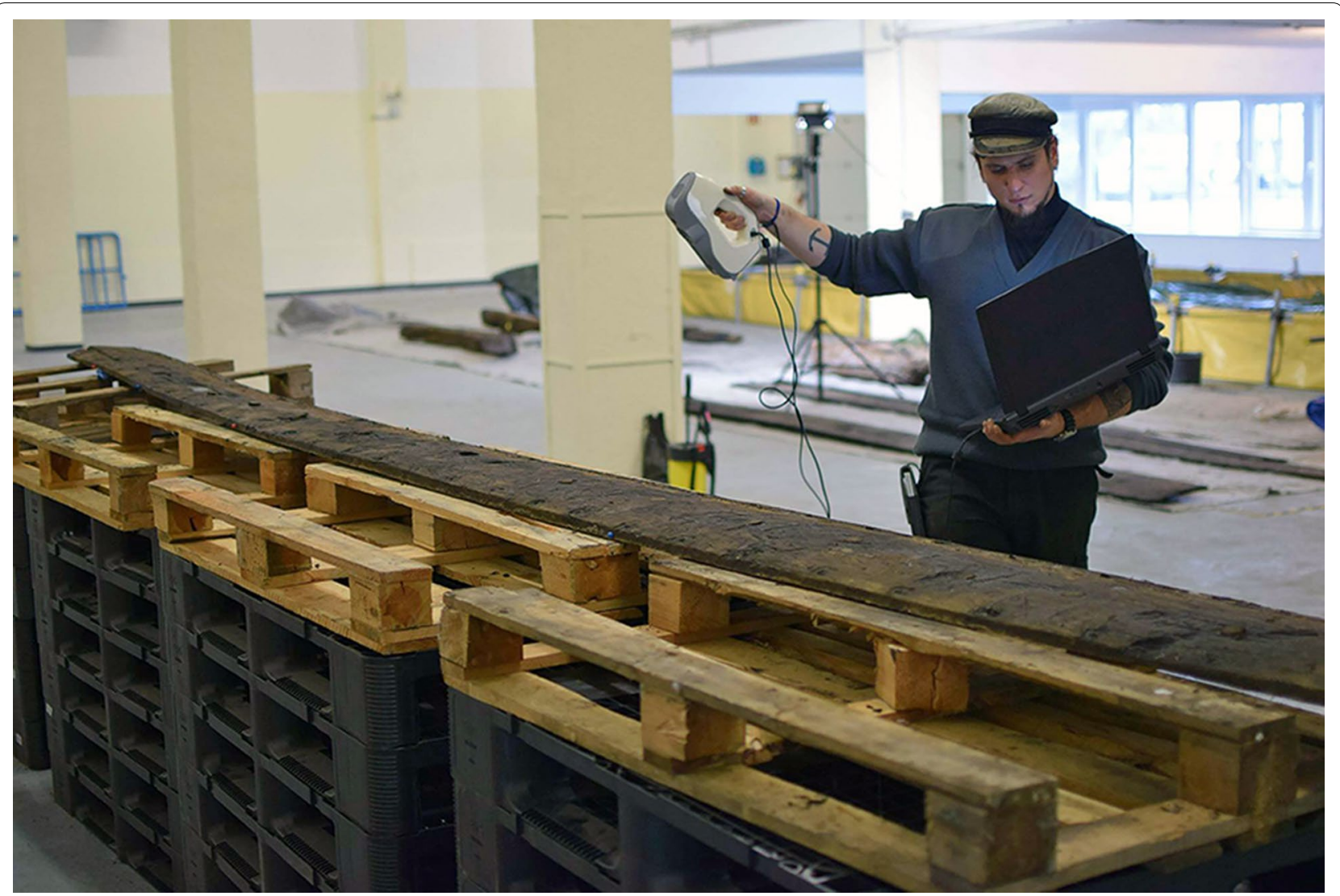

Fig. 6 Scanning a rigid plank using the Artec Eva handheld scanner. Notice the small blue and red reference pins inserted along the plank's edge 


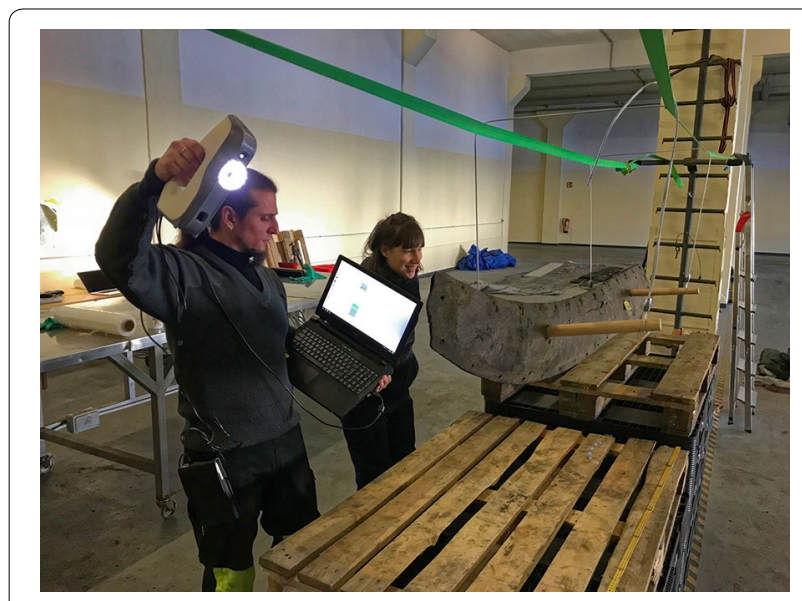

Fig. 7 Scanning a long, flexible plank using the Artec Eva handheld scanner. To avoid changes in shape when the plank is turned over, the plank is suspended above the documentation table and recorded in a single scan

elements, comprising a total of 194 ship timbers (which sometimes consisted of several broken parts) were recorded in detail. Small timber fragments without visible features were examined and registered, but not recorded. The following overview outlines the 3D annotated scans approach to timber recording, as implemented on this project.

\section{D scanning}

For the initial 3D scanning phase, the Artec Eva handheld structured-light 3D scanner-which records both object geometry and texture-was chosen as the main recording tool, following positive experiences with this device on the first project. Prior to scanning, several factors must be taken into consideration. To avoid interference with the structured-light system, scanning should be carried out indoors, out of direct sunlight. Reflections can likewise lead to errors, so after cleaning, timber surfaces should be blotted dry with a towel. ${ }^{2}$ Finally, the scanner tracks its location using both geometry and texture information, so it is advised to place the timbers on a surface which contains both distinctive geometry and texture features; in our case, simple wooden pallets proved to be an ideal background for scanning.

\footnotetext{
${ }^{2}$ Note that in order to avoid damaging the wood, waterlogged timbers should be kept wet at all times. In our case, every morning small batches of timbers were taken out of the water basins for scanning; these were carefully covered with textile and regularly sprayed with water to keep them wet. The timbers' surfaces were then simply patted dry immediately prior to scanning in order to avoid water reflections.
}

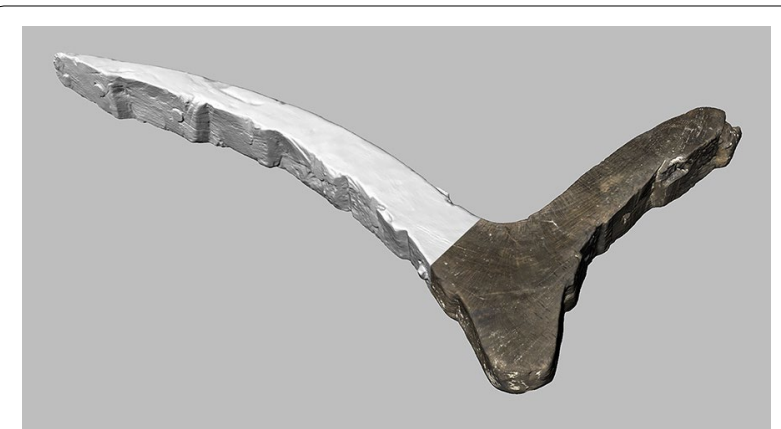

Fig. 8 3D scan of a ship timber, captured with the Artec Eva. Composite image showing the 3D model's base geometry (left) and geometry with texture (right)

In general, the workflow then consisted of making several overlapping scans of each timber, and subsequently combining these scans into a single model using the Artec Studio software. While the scanning itself could normally be carried out by one person, a scanning team of two was found to be ideal as the second person could assist in positioning the timbers (the entire documentation team helped with the handling of larger timbers) and could be at work post-processing the timber scans while the other person was scanning.

During recording, the scanner was connected to a laptop and to a portable battery, allowing the recorder to move freely around the timber, and to see the 3D model being captured in real-time on the computer screen (Figs. 6, 7). Sturdy four-sided timbers were the easiest to record; they could be placed directly on the pallets and were simply recorded in two scans, one per side. For planks, the recording setup varied depending on the plank's robustness and length. Rigid planks were placed flat on the pallet table and were likewise captured in one scan per side. However, since the thin edges of most of the planks offered little in terms of visual reference, matt coloured drawing pins were distributed along the edges to serve as reference points when combining the two scans (Fig. 6). Short flexible planks were supported by sandbags and placed standing upright on their long edge in order to avoid changes to their shape when turned over. After the first scan, the planks were then positioned on their opposite long edge and scanned a second time. In between both scans the sandbags were moved to ensure that each plank face could be fully captured in at least one scan. The sandbags were then removed from the resulting scan data in Artec Studio before merging both scans. Another method was used for particularly long and flexible planks. In order to maintain their natural curvature and to avoid changes in shape when the timber was turned over, such planks were suspended above 


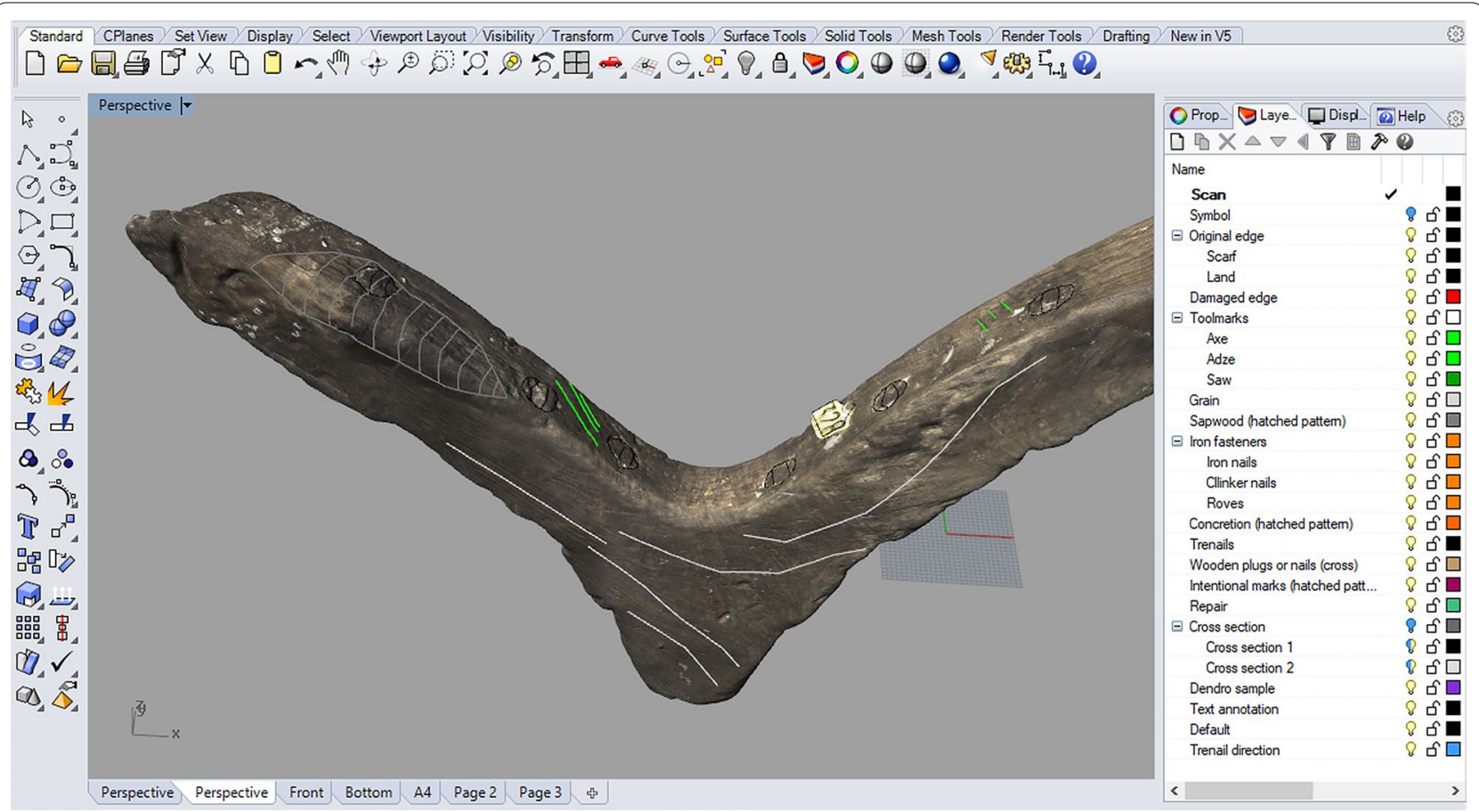

Fig. 9 Rhino user interface, showing a 3D annotated timber scan (left) and the different coloured layers representing different feature types (right)

the documentation table prior to recording. To do this, trenails were removed in two or more places along the plank's length and replaced by round wooden pegs of the same diameter. Using thin ropes secured to these pegs, the planks could then be suspended from a support structure, thereby allowing the complete plank to be recorded in a single scan (Fig. 7).

While one person was scanning, another person was responsible for processing the resulting timber scans on a custom-built PC. In terms of processing, the background of each scan was first removed in Artec Studio. The individual scans were then aligned, either automatically, or manually using reference points. Following successful alignment, the 'Global Registration' command was used to optimise the alignment of the individual scans and to combine them into a single model of the timber. After removing noise and unwanted objects from the scan, the 'Sharp Fusion' command was used to create a watertight mesh, which could then be simplified and textured. The resulting textured mesh, exported as a solid 3D model in OBJ format, served as an objective digital 3D reproduction of the physical timber, ready for annotation (Fig. 8).

\section{D annotation}

In order to add archaeological interpretation to the timber scan, the OBJ file was then imported into Rhinoceros 5.0. In Rhino, a layering convention similar to that used for contact digitising was implemented. Different coloured layers represented different feature types such as wood grain, trenails, nails, repairs, toolmarks and intentional markings. Whereas with contact digitising these features are physically traced using the pen of a coordinate measuring device, in this approach the features were traced digitally using the 'PolylineOnMesh' command in Rhino, which allowed users to draw 3D polylines directly onto the textured mesh (Fig. 9). During the annotation process researchers went back and forth between examining the physical timber and then tracing all significant features onto the digital copy of the timber. A notable difference with contact digitising is that it was not necessary to trace all the timber edges, since these were already stored in the mesh geometry. In order to show the timber's orientation relative to the wreck as a whole, a stick figure and fish symbol were used to designate the timber's inboard and outboard surfaces respectively, with both symbols facing towards the forward end of the wreck.

As such, the end result of the 3D annotated scans method consists of a digital 3D record containing both an objective digital copy of the timber, as well as the archaeologist's interpretation of that timber layered on top. Besides saving the files in Rhino's proprietary 3DM format, the textured timber mesh and polyline interpretation layers can also be saved in DWG format to ensure full compatibility with other CAD software such as AutoCAD. On the Wismar Big Ship Project this 3D record was 
$<$ Port

(ब)
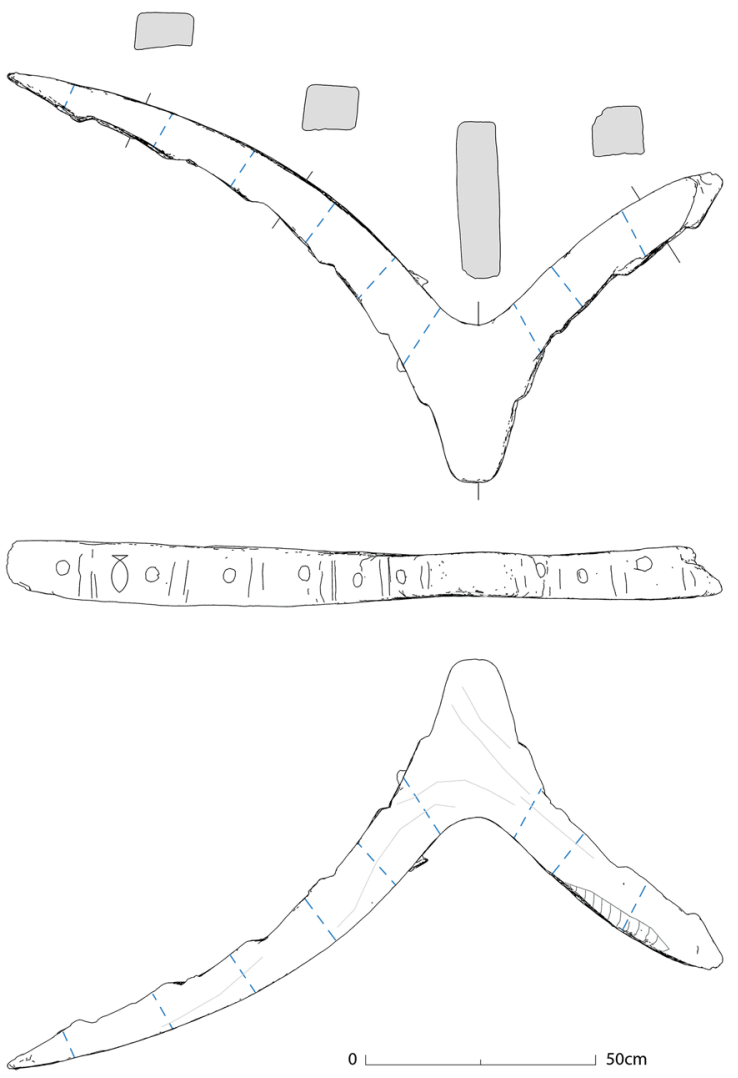

Starboard >
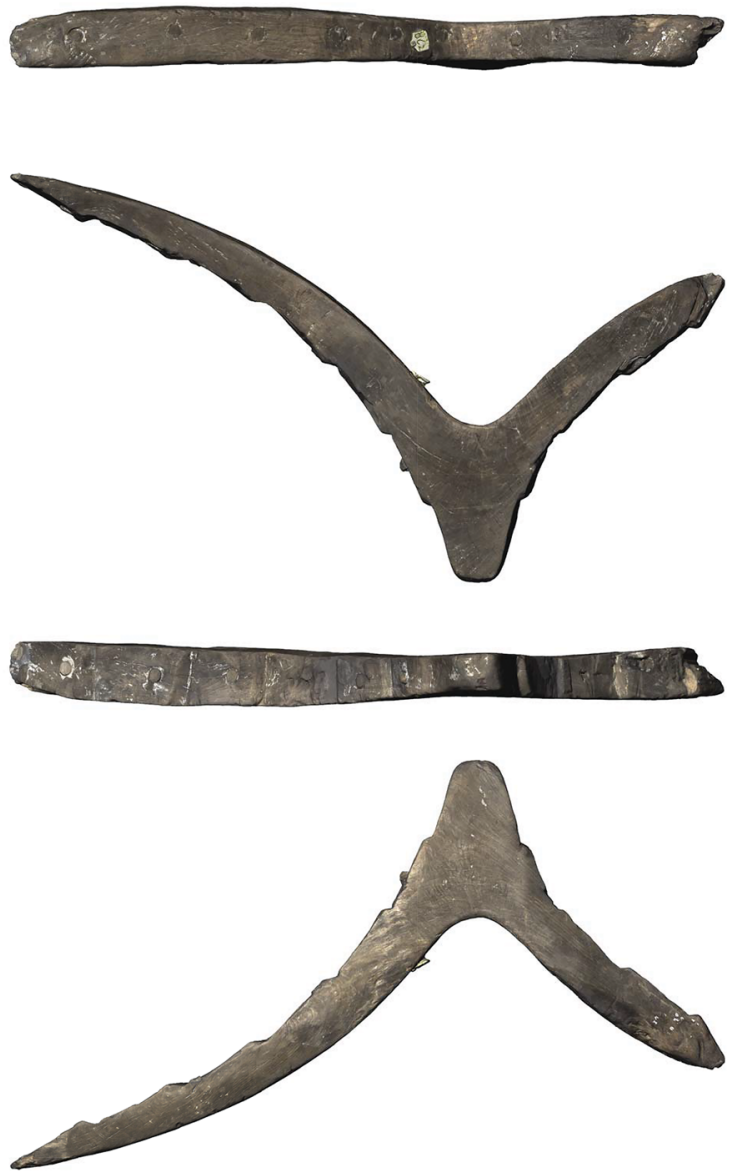

- Wooden plug - Intentional marks

- Damaged edge

--- Lofted trenail

\section{Mecklenburg}

Vorpommern

Landesamt für Kultur und

Fig. 10 Example of a four-sided timber catalogue entry of the Wismar Big Ship, showing the 'Technical'view mode (left) and 'Rendered' view mode (right)

further supplemented with a short, written description of each timber, as well as pictures of important details. The interpretation was based on the physical timbers as well as on relevant data from the excavation, such as site plans or notes. In general, two members of the documentation team were responsible for timber annotation. In order to ensure that the dataset was as consistent as possible, the 3D annotation and written interpretation of each timber were carried out by the same person. Standardised templates and documentation guidelines helped to further harmonise the process.

\section{Additional outputs}

After documentation, the resulting 3D timber records were used to produce a full 2D timber catalogue of the wreck, and to reassemble the wreck both digitally in CAD software, and physically, using 3D printed models of the timbers. While these additional steps don't form part of the 3D annotated scans recording method itself, 


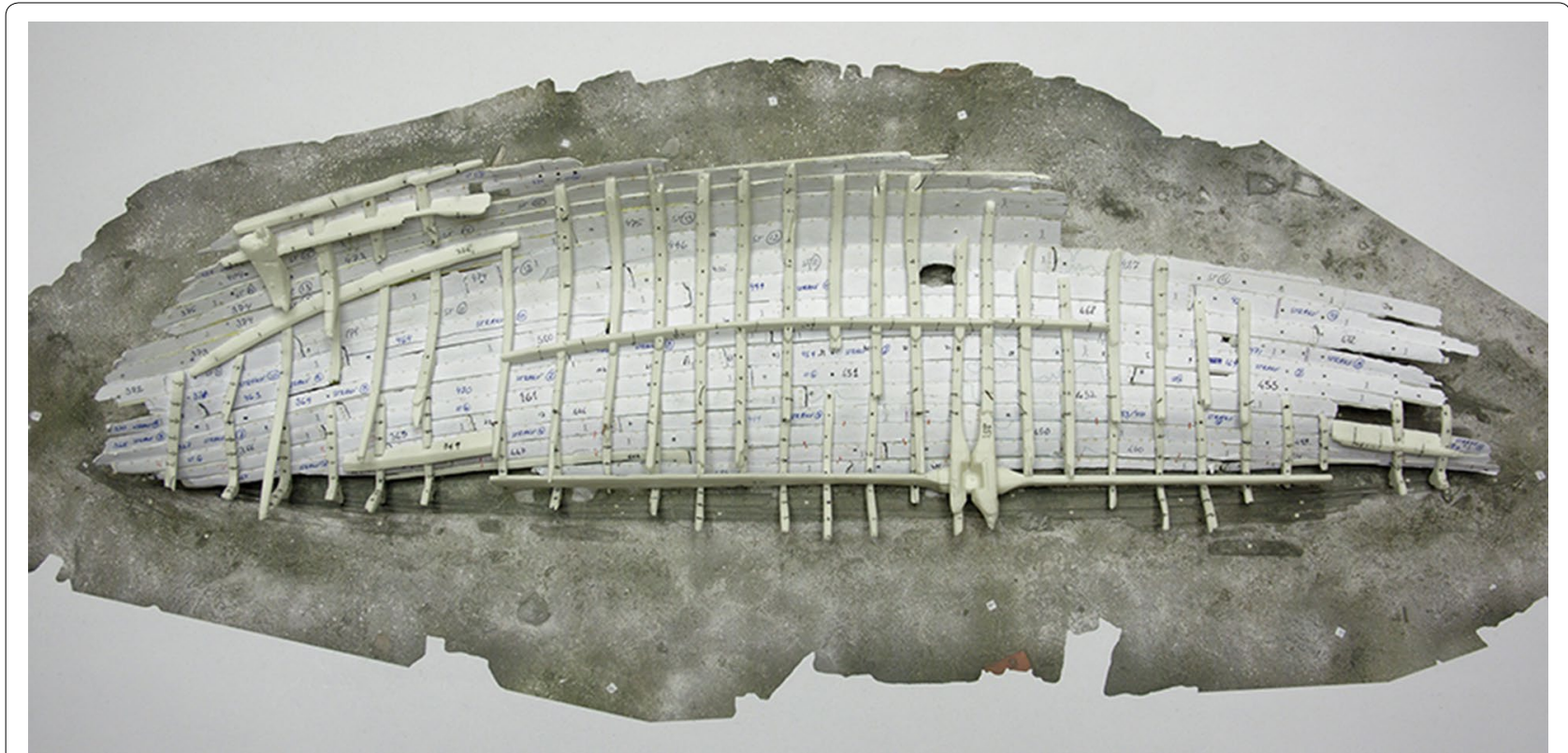

Fig. 11 Physical 'as found'reconstruction of the Wismar Big Ship at scale 1:20, reassembled using 3D printed timber scans. The scale model is positioned on top of the photogrammetry site plan

they serve to illustrate how the data acquired using this approach can be used for further publication and analysis purposes.

In order to create a $2 \mathrm{D}$ timber catalogue entry for each timber, Rhino's various 'Drafting' and 'Rendering' tools were used. First, after annotating a timber scan, cross sections of the timber were produced at intervals using the 'Section' command, and polylines connecting trenail ends were drawn in order to show the direction in which trenails were inserted. Using the 'Drafting' tools, several standardised Rhino layouts were then created, in which each face of the timber (two faces for planks and other 'flat' timbers, four faces for frames, cross beams and similar four-sided timbers) was shown at scale 1:10 on a (digital) sheet of paper ranging in size from A4 to A0 (depending on the size of the timber). Once these templates had been made, the user simply had to choose the most appropriate template for any given timber, and the 2D timber catalogue entries could then be exported in PDF format. For each timber, two layouts were exported: one in Rhino's 'Rendered' view mode and one in the 'Technical' view mode. The Rendered view mode provides a full render of each face of the timber's textured mesh, emphasising colour information and the surface structure of the wood. The Technical view mode emphasises the timber's technical details; it depicts the timber scan's outlines as a series of black lines, similar to a traditional lines drawing, on top of which the timber's annotated features such as fastenings and toolmarks are displayed as coloured lines. Cross sections show the geometry of the timber at given stations, trenails directions are illustrated as dotted lines, and the stick figure and fish symbol show the timber's orientation relative to the wreck. After exporting the 2D timber catalogue entries as PDFs, the written timber descriptions were added, and all files were compiled into an overall timber catalogue in Adobe Illustrator CC (Fig. 10).

The 3D timber scans were also used to produce an as found' reconstruction of the wreck. First, over the course of the project, as new timbers were recorded, their 3D models were gradually reassembled digitally in Rhino. During the recording stage this working document proved useful in order to better understand the relationships between individual timbers. Then, once all timbers had been recorded, they were 3D printed at scale 1:20 and reassembled physically using metal wire and screws (Fig. 11). The model was built during the reporting stage and proved to be an invaluable tool for the construction analysis, as well as helping to determine the position of timbers found out of context. It might also serve as the basis for a tentative reconstruction in the future.

\section{Discussion}

Now that the reader has an understanding of what the 3D annotated scans method entails conceptually, and how it might be implemented in practice, in this section the method's respective advantages and limitations will be 
assessed in light of the scientific and practical considerations discussed in the "Considerations when choosing a recording method" section. While this assessment is based on the authors' experience recording the timbers of the Wismar Big Ship, other potential implementations of the method are taken into consideration as well.

\section{Scientific considerations \\ Accuracy}

The overall accuracy of the 3D annotated scans method depends on both the accuracy of the underlying 3D scans, and on the accuracy with which the timber's features are subsequently traced during the $3 \mathrm{D}$ annotation phase.

As discussed above, the 3D scanning methods currently used by archaeologists for timber recording are generally considered extremely accurate, and any such method which captures both object geometry and colour can be used during the initial 3D scanning phase of the 3D annotated scans approach. The Artec Eva scanner used on the Wismar Big Ship Project has a stated accuracy of up to $0.1 \mathrm{~mm}$, a geometric resolution of up to $0.5 \mathrm{~mm}$ and a texture resolution of 1.3 megapixels per frame (the final object texture typically consists of dozens of merged frames) [20]. Given that traditional shipbuilders likely weren't working at sub-millimetre levels of precision, this should be more than enough for most maritime archaeological applications. As such, using the appropriate tools, $3 \mathrm{D}$ scanning allows the recorder to capture the timber's geometry and colour to a level of accuracy and detail that simply can't be matched using traditional recording methods. Furthermore, this accuracy will likely continue to improve in the future as better scanning hardware, software and workflows are developed.

Regarding the 3D annotations, their accuracy depends on the person doing the recording. However, much like with 3D contact digitising, there is little risk of measurement or drawing errors, since the recorder simply has to trace the timber's features on the 3D scan. As such, so long as the annotator takes care to precisely follow each feature's outline, the accuracy of the 3D annotations will be on a par with the accuracy of the 3D scans. The most challenging features to trace are small details such as nail holes, which may not always be clearly discernible on the timber's 3D model. The more detailed the underlying scan, the easier it will be to pin-point and trace the precise locations of such features. Nevertheless-regardless of a scan's resolution-it remains crucial to have the actual physical timber available during annotation.

\section{Dvs $3 D$}

With the 3D annotated scans approach, timbers are recorded in 3D, thereby avoiding the loss of information inherent to 2D recording. The Wismar Big Ship case study illustrates how this 3D data can be helpful for further analysis of the shipwreck, and how it can be efficiently converted to a $2 \mathrm{D}$ format as needed.

\section{Interpretation vs scanning}

One of the core strengths of the 3D annotated scans method is that the resulting timber record contains both an objective and complete digital copy of the physical timber, as well as that timber's in-depth archaeological interpretation, all in one coherent 3D output. As such, the method combines the advantages of 3D scanning with the indispensable step of actually examining and interpreting the physical timbers.

Furthermore, the immediate availability of 3D solids proved useful in order to reassemble the wreck digitally during the recording stage, and then physically during the reporting stage. As a result, in addition to interpreting each timber individually, this workflow also allowed for a better understanding of the relationships between different timbers, and for a more comprehensive interpretation of the wreck as a whole.

\section{Practical considerations Cost and time efficiency}

As with any recording method, the most obvious expense associated with the 3D annotated scans method is the cost of the tools required to carry out the recording; in this case the 3D scanning hardware and software, the 3D annotation software and the necessary computers to process the scan data and to annotate the timbers. In terms of scanning hardware, an Artec Eva handheld scanner such as the one used in our case study is by no means cheap, but it is considerably more affordable than many other 3D scanning tools such as terrestrial laser scanners and laser line probes. In terms of software, Artec Studio came bundled with the scanner, and while Rhinoceros is again relatively costly, it is also significantly cheaper than most CAD software alternatives. In terms of computer hardware, at least one powerful computer was needed to process the scan data, but 3D annotation could simply be carried out on the participants' personal laptops.

However, as noted above, other tools can be used, and for most projects the most significant factor contributing to a recording method's cost will not be the cost of the hardware or software, but rather the time expenditure per timber. Using the 3D annotated scans method, on the Wismar Big Ship Project a team of four people equipped with a single Artec Eva scanner, working $10 \mathrm{~h}$ a day, were able to clean, scan, annotate, photograph and describe 
240 timber elements in a mere 37 days. This adds up to an average of 6.5 timbers per day. Interestingly, two people scanning and processing timber scans were able to complete 8 to 10 timber scans a day, meaning that in our approach the main bottleneck was not the scanning hardware itself, but rather the speed at which the two remaining researchers could subsequently annotate and describe the timbers. Nevertheless, as seen in the "Considerations when choosing a recording method" section, other 3D scanning methods may achieve an even higher timber scanning output per device per day, so it is important to keep an open mind when deciding on which $3 \mathrm{D}$ scanning tools to use.

Out of the traditional timber recording methods discussed, only 3D contact digitising would have provided the desired scientific results, namely an interpreted 3D record of each timber. However, as mentioned above, this method was considered too time-consuming for the development-led projects in question. Based on the estimated recording times for two-sided and four-sided timbers on the Newport Ship Project (5; Jones 2018, personal communication), assuming an experienced contact digitising expert and supporting staff were hired, working $10 \mathrm{~h}$ per day, contact digitising of 240 timber elements on the Wismar Big Ship Project would have taken roughly 123 days to complete, or an average of about 2 timbers recorded per day. Since in this approach the main bottleneck is the hardware itself, the only way to speed up recording would be to purchase additional contact digitisers, which in general are considerably more expensive than, for instance, an Artec Eva.

Furthermore, in terms of producing useful outputs, after recording the timbers using $3 \mathrm{D}$ contact digitising, an estimated 480 labour hours would be needed to convert the 3D polylines into simplified digital solids for 3D modelling and printing (5; Jones 2018, personal communication). By contrast, on the Wismar Big Ship Project, using the 3D annotated scans method, significantly more detailed 3D solids were immediately available, requiring no extra work on the part of the researchers. As a result, this data could be used to reassemble the wreck digitally at the same time as timbers were being recorded, thereby providing an additional level of interpretation. Finally, after recording was completed, it took a single person 10 days to produce a detailed 2D catalogue of all $240 \mathrm{tim}$ ber elements, and building the 'as found' reconstruction from the 3D printed timber models took one archaeologist a further 3 days.

As such, in terms of cost and time efficiency, we believe the 3D annotated scans method compares very favourably to $3 \mathrm{D}$ contact digitising, while producing similar accurate, interpreted 3D timber records, as well as a more objective, detailed and textured 3D model of each timber. $2 \mathrm{D}$ tracing may be as fast as the $3 \mathrm{D}$ annotated scans method-and certainly cheaper in terms of recording hardware-but this approach is less accurate and doesn't produce 3D records. Similarly, 2D scaled drawing is also less expensive in terms of hardware, but the method is more time-consuming than the $3 \mathrm{D}$ annotated scans method, while again producing less accurate, twodimensional results.

\section{Required technical expertise}

One limitation of the 3D annotated scans method is that both 3D scanning and 3D annotation do require some technical expertise to carry out. In the case of the Wismar Big Ship Project, three out of four participants had prior experience working with the method, and the fourth participant was a maritime archaeologist with a technical background in 3D scanning.

Whichever 3D scanning method is chosen, certain obstacles will inevitably come up while scanning timbers, and not everyone has the technical experience or insight required to overcome these issues. Nevertheless, in the authors' experience, once a suitable scanning setup had been established for different timber types, scanning using the Artec Eva was relatively straightforward, and teaching a new user the basics of working with the scanner and the accompanying software generally took only a matter of hours. Furthermore, it should be kept in mind that the 3D scanning phase doesn't necessarily need to be carried out by archaeologists; it can just as readily be delegated to a 3D scanning specialist, without compromising the scientific value of the final results.

By contrast, the 3D annotation phase should most certainly be carried out by maritime archaeologists, and working with the necessary CAD software-in this case Rhinoceros-likewise requires training. Fortunately many maritime archaeologists already have experience working with this software, and again, on the projects discussed above, even users with no prior Rhino experience could be taught how to 3D annotate timber scans in a matter of hours.

As such, while the 3D annotated scans method does require more technical expertise and preparation to use when compared to for instance 2D scaled drawing or 2D tracing, this limited extra effort is relatively insignificant when balanced against the method's advantages. Archaeologists have proven quite capable of adapting to new technological developments in the past, and where necessary outside expertise can always be called upon to assist in timber recording or in training team members in the use of new methods. While this may be less feasible on small impromptu projects, it certainly holds true for any large pre-planned timber recording project. 
Again, a related issue is the technical expertise required for other researchers to work with the resulting timber records. As we have seen, the underlying scans can be stored in the widely used open-source OBJ format, and both the scans and the annotation layers can be saved in 3DM and DWG format, thereby ensuring compatibility with commonly used CAD software such as Rhinoceros and AutoCAD. Although there is currently no opensource file format providing full data parity across all CAD programs, the proprietary DWG format is the most widely supported, and is therefore recommended by the Archaeology Data Service for the archiving of CAD data [21]. Furthermore, by exporting the 3D data as a 2D timber catalogue, both the (simplified) geometry and texture of the scans, as well as the timbers' archaeological interpretation, remain accessible to researchers unaccustomed to working with 3D software. As an added benefit, the resulting PDF files are generally considered futureproof, thereby providing an extra data archiving safeguard at a time when it is still somewhat unclear which 3D file formats will remain accessible in the future.

\section{Ease of use in the field}

The ease with which the 3D annotated scans method can be used in the field depends mainly on the 3D scanning method chosen. Certain methods, such as photogrammetry, can readily be used in a rugged fieldwork environment, whereas others are more suited to a laboratory setting. As long as electricity is available, scan processing and $3 \mathrm{D}$ annotation can be done on a laptop, so computer hardware shouldn't be an impediment to using the 3D annotated scans method in the field. On the Mönchgut, Ostsee VII, Fpl. 63/64 Project, the portability of the Artec Eva handheld scanner was a major advantage; during the working day the scanner was used in the temporary recording tent, after which it could easily be moved and stored in a safe location overnight. Nevertheless, ambient sunlight penetrating the white canvas of the tent would sometimes interfere with the structured-light system, so on the later Wismar Big Ship Project the scanner was used indoors.

\section{Conclusion}

As long as researchers make use of suitable 3D scanning tools and take care to precisely trace features onto the timber scan, the 3D annotated scans method will result in an accurate and detailed 3D record containing both an objective digital copy of the timber's geometry and texture as well as the timber's archaeological interpretation. As such, in terms of scientific output, the 3D annotated scans method matches and in certain regards surpasses the current best practice method for timber recording, namely $3 \mathrm{D}$ contact digitising. Furthermore, although the method requires some training to use, it will generally be significantly more cost and time efficient than 3D contact digitising, and it is easier to use in the field.

Overall, in combining the speed, accuracy and level of detail of 3D scanning with in-depth 3D archaeological interpretation, the 3D annotated scans method represents another incremental improvement in the transition from traditional analogue $2 \mathrm{D}$ recording methods to more complete, digital 3D recording-a transition which, for ship timber recording, began with the introduction of 3D contact digitising some 20 years ago. It is important to point out that the accuracy, level of detail, cost and time efficiency and ease of use (in the field or otherwise) of the 3D annotated scans method will continue to improve as new 3D scanning tools and workflows are developed and implemented by archaeologists. However, much as specific implementations of the 3D annotated scans method will continue to evolve, researchers must also keep an open mind towards experimenting with and implementing entirely new approaches to timber recording which may arise.

Since initially developing and testing this approach to timber recording, the 3D annotated scans method has been successfully used on a number of other shipwreck projects including the 15th Century Vistula River Vessel in Czersk, Poland and the 19th Century Barangaroo Boat in Sydney, Australia. Furthermore, the same approach is also currently being used by conservators of the LAKD $\mathrm{M}-\mathrm{V}$ to record and annotate archaeological objects prior to conservation, and to document changes during the conservation process. As such, while the method was initially developed for ship timber recording, it can be used for a wide range of heritage applications (and beyond) including the documentation of other types of archaeological objects and features, the recording of museum collections, conservation treatment and historical monument care.

\section{Abbreviation}

LAKD-MV: State Authority for Culture and Monuments in Mecklenburg-Western Pomerania (Landesamt für Kultur und Denkmalpflege Mecklenburg-Vorpommern).

\section{Acknowledgements}

We would like to thank all the authors and photographers who responded to our request for pictures of current ship timber recording methods, and who kindly granted us permission to use their pictures in our article, including Kester Keighley, Drew and Carrie Fulton, Nichole Doub, Christian Lemée, Johan Opdebeeck, Alice Overmeer, Heidi Vink, Toby Jones and Chris Dostal. Unfortunately we had to make a selection and not everyone's images could be included in the final article. We would also like to express our gratitude to Toby Jones for many insightful discussions, and for providing us with time estimates for timber recording using 3D contact digitising on the Newport Ship Project.

\section{Authors' contributions}

TVD, JA and MD contributed to the 3D annotated scans method's development. Timber recording on the Wismar Big Ship Project was carried out by 
MD, JA, MC and Benjamin Halkier. MC produced the final 2D timber catalogue and $M D$ created the digital and physical 'as found' reconstructions of the wreck. TVD, JA, MD and MG contributed to the content and structure of the manuscript. Final editing of the manuscript was done by TVD. All authors read and approved the final manuscript.

\section{Funding}

Writing of the current article was done in the authors' own time, without external funding. The development-led archaeological projects during which the 3D annotated scans method was developed and implemented were carried out by the State Authority for Culture and Monuments in Mecklenburg-Western Pomerania (Landesamt für Kultur und Denkmalpflege Mecklenburg-Vorpommern).

\section{Availability of data and materials}

The 3D timber records of the Wismar Big Ship are not currently publicly available, but are accessible to researchers upon request to the authors. The 2D timber catalogue and further details about the wreck site will be included in the forthcoming project publication.

\section{Code availability}

Artec Studio, Rhinoceros and Illustrator CC are proprietary software packages. The software code is developed and owned by Artec 3D, Robert McNeel \& Associates and Adobe Inc respectively.

\section{Competing interests}

The authors declare that they have no competing interests.

\section{Author details}

${ }^{1}$ Ubi3D, Antwerp, Belgium. ${ }^{2}$ State Authority for Culture and Monuments in Mecklenburg-Western Pomerania, Schwerin, Germany. ${ }^{3}$ Stavanger Maritime Museum, Stavanger, Norway. ${ }^{4}$ University of Gdańsk, Gdańsk, Poland.

Received: 5 May 2020 Accepted: 11 July 2020

Published online: 31 July 2020

\section{References}

1. Muckelroy K. Maritime archaeology. Cambridge: Cambridge University Press; 1978.

2. Adams JR. A maritime archaeology of ships: innovation and social change in late medieval and early modern Europe. Oxford: Oxbow Books; 2013.

3. Steffy R. Wooden shipbuilding and the interpretation of shipwrecks. College Station: Texas A\&M University Press; 1994.

4. Fix PD. Archaeological watercraft: a review and critical analysis of the practice. College Station: Texas A\&M University; 2015.

5. Jones T. Three-dimensional digital recording and modelling methodologies for documentation and reconstruction of the Newport Medieval Ship. Carmarthen: University of Wales Trinity Saint David; 2015.

6. Ravn M, Bischoff V, Englert A, Nielsen S. Recent advances in postexcavation documentation, reconstruction, and experimental maritime archaeology. In: Catsambis A, Ford B, Hamilton DL, editors. The Oxford Handbook of maritime archaeology. Oxford: Oxford University Press; 2012. p. 232-49.
7. Bowens A, editor. Underwater archaeology: the NAS guide to principles and practice. Portsmouth: Blackwell Publishing; 2009.

8. Fulton C. Photographs into Models: Documenting the World Trade Center Ship. Society for Historical Archaeology. 2014 https://sha.org/ blog/2014/11/photographs-into-models-documenting-the-world-trade -center-ship/. Accessed 8 July 2020

9. Crumlin-Pedersen O. The Skuldelev ships: topography, archaeology, history, conservation and display. 1: Ships and boats of the north. Roskilde: Viking Ship Museum; 2002.

10. Dostal CM. Laser scanning as a methodology for the 3-D digitization of archaeological ship timbers: a case study using the World Trade Center Shipwreck. College Station: Texas A\&M University; 2017.

11. Fiedler K. Large clinker built cargo vessels from the late medieval period in Northern and Western Europe-The Mönchgut 92 wreck in context. Odense: University of Southern Denmark; 2016.

12. Schwarz G. Reconstructing Naval History: The 3D Scanning of Royal Savage. Naval History and Heritage Command. 2015. https://usnhistory.navyl ive.dodlive.mil/2015/12/23/reconstructing-naval-history-the-3d-scann ing-of-royal-savage/. Accessed 26 Mar 2020.

13. Van Damme T. 3D-fotogrammetrie. In: Waldus WB, editor. De opgraving en lichting van de 15e-eeuwse IJsselkogge. Amersfoort: ADC ArcheoProjecten; 2018. p. 87-93.

14. Żrodowski C. An attempt to create a digital reconstruction of the copper ship. In: Ossowski W, editor. The copper ship: a medieval shipwreck and its cargo. Gdańsk: National Maritime Museum; 2014. p. 197-238.

15. Baker PE, Green JN. Recording techniques used during the excavation of the Batavia. Int J Nautical Archaeol. 1976;5(2):143-58.

16. Nayling N, Jones T. The newport medieval ship, Wales, United Kingdom. Int J Nautical Archaeol. 2014;43(2):239-78.

17. Ravn M. Recent advances in post-excavation documentation: Roskilde Method. In: Günsenin N, editor. Between Continents Proceedings of the Twelfth Symposium on Boat and Ship Archaeology Istanbul 2009. Istanbul: Ege Yayınları; 2012. p. 313-7.

18. Auer J, Grabowski M, Van Damme T. Excavation and recovery of wrecks Ostsee Bereich VII, Mönchgut Fpl. 63 (7070) and Fpl. 64 (7071) and in situ protection of wreck Fpl. 65 (7072). Archaeological Diving Operation. Ref.3544-5409.01. Schwerin: Landesamt für Kultur und Denkmalpflege; 2018.

19. Auer J, Ditta M. Bergung und Dokumentation des Bodendenkmals Wismar, Ostsee II, Fpl. 32 im Rahmen des Projektes "Seehafen Wismar, Fpl. 32"(3544-5504). Ref.3544-5504.01. Schwerin: Landesamt für Kultur und Denkmalpflege; 2019

20. Artec 3D. Artec Eva. Artec 3D. 2020. https://www.artec3d.com/portable3d-scanners/artec-eva. Accessed 26 Mar 2020.

21. Eiteljorg II H, Fernie K, Huggett J, Robinson D. CAD: A guide to good practice. Archaeology Data Service/Digital Antiquity: Guides to Good Practice. 2011. https://guides.archaeologydataservice.ac.uk/g2gp/Cad_Toc. Accessed 26 Mar 2020.

\section{Publisher's Note}

Springer Nature remains neutral with regard to jurisdictional claims in published maps and institutional affiliations. 